Mercadé Aloy, J., Magrinyà Torner, F., Cervera Alonso de Medina, M. (2020): "Revelando las centralidades del transporte público mediante SIG y GTFS: una propuesta de reequilibrio urbano para el Área Metropolitana de Barcelona", GeoFocus, $n^{\circ} 25$, p. 27-46. http://dx.doi.org/10.21138/GF.657

\title{
REVELANDO LAS CENTRALIDADES DEL TRANSPORTE PÚBLICO MEDIANTE SIG Y GTFS: UNA PROPUESTA DE REEQUILIBRIO URBANO PARA EL ÁREA METROPOLITANA DE BARCELONA
}

\author{
JOSEP MERCADÉ ALOY ${ }^{1}$, FRANCESC MAGRINYÀ TORNER ${ }^{2}$, MARINA CERVERA \\ ALONSO DE MEDINA ${ }^{3}$ \\ Universitat Politècnica de Catalunya \\ C. Jordi Girona, 1-3. 08034 Barcelona, España \\ 1josep.mercade@upc.edu, ${ }^{2}$ francesc.magrinya@upc.edu, ${ }^{3}$ marina.cervera@upc.edu
}

\section{RESUMEN}

Este artículo se dedica a establecer el grado de centralidad, basada en la accesibilidad conferida por el transporte público, de la estructura urbana del Área Metropolitana de Barcelona. Asimismo, se plantea una estrategia de refuerzo de ciertos intercambiadores potenciales de la red ferroviaria, dirigida al reequilibrio urbano del conjunto.

El paisaje de accesibilidades se construye asumiendo la misma importancia para cualquier origen en suelo urbano, analizando su relación de posición con el resto de lugares. Se utiliza el formato GTFS (General Transit Feed Specification) disponible para caracterizar las impedancias y se representan los resultados con isócronas de accesibilidad.

Los resultados revelan la cartografía del espacio-tiempo metropolitano, mientras que la propuesta de intensificación de las oportunidades de intercambio permite una mayor integración de los ejes estratégicos del sistema metropolitano.

Palabras clave: Centralidades; accesibilidad; isócronas de accesibilidad; GTFS; SIG

REVEALING CENTRAL PLACES OF PUBLIC TRANSIT USING GIS AND GTFS:

AN URBAN REBALANCING STRATEGY FOR THE METROPOLITANA AREA OF BARCELONA

\section{ABSTRACT}

This paper is devoted to establishing the degree of accessibility-based centrality of the urban structure conferred by public transit at the Metropolitan Area of Barcelona. Additionally, the strengthening of certain railway hubs is considered, with a view towards rebalancing the whole urban system. 
Mercadé Aloy, J., Magrinyà Torner, F., Cervera Alonso de Medina, M. (2020): "Revelando las centralidades del transporte público mediante SIG y GTFS: una propuesta de reequilibrio urbano para el Área Metropolitana de Barcelona", GeoFocus, $n^{\circ} 25$, p. 27-46. http://dx.doi.org/10.21138/GF.657

A landscape of accessibility is revealed, assuming that opportunities are the same everywhere, by evaluating de total distance from each place to all others. The impedances are based on GTFS (General Transit Feed Specification), while the results are displayed via isochrones.

The results show the metropolitan space-time cartography, whereas the proposal of increasing intermediacy allows for a better integration of strategic places and corridors.

Keywords: Centrality; accessibility; isochrones; GTFS; GIS

\section{Introducción}

Este artículo plantea un método para identificar las centralidades urbanas que propone la red de transporte público a partir de la evaluación de la accesibilidad, con la finalidad de poner de manifiesto su potencial e informar estrategias de reequilibrio urbano en el Área Metropolitana de Barcelona.

La estrategia de inserción, refuerzo y/o consolidación de nuevas centralidades urbanas, especialmente las vinculadas a ciertos umbrales de accesibilidad ferroviaria, se ha considerado indispensable para conferir valor y urbanidad a las transformaciones urbanas actuales y de finales del pasado siglo XX. Así se recoge en la producción científica, la literatura especializada (ver, p. ej., Busquets, 1989) y el planeamiento de escala territorial o regional (ver, p. ej., Generalitat de Catalunya, 2010)

La noción de centralidad comprende un amplio espectro de situaciones a considerar. Así, desde la construcción ex novo y de periferia de centralidades de la producción, del consumo y los parques tecnológicos y de oficinas (ver, p. ej., Font et al., 2012), hasta las operaciones más complejas de reciclaje, encaminadas, en el mejor caso, a conferir urbanidad mediante el reequilibrio interno entre sectores de la misma ciudad en el sentido expresado por Busquets (1989), existe un sinfín de escenarios, categorías y escalas de influencia de dichas concentraciones de masa crítica. En cualquier caso, la accesibilidad con transporte público es un ingrediente indispensable en un modelo de ciudad sostenible.

De nuevo, la accesibilidad se presenta como un concepto complejo que abarca múltiples aproximaciones (Hanson, 1986). En este artículo se plantea el uso del formato común General Transit Feed Specification (GTFS), que permite a las agencias de transporte público almacenar sus datos (para una revisión del concepto GTFS ver, p. ej., McHugh, 2013), para caracterizar el escenario actual y proponer simulaciones de mejora. Por otro lado, se propone rescatar una forma clásica de representación de la accesibilidad: la visualización de isócronas de accesibilidad a partir del cálculo de caminos mínimos y el tiempo de viaje asociado.

El objetivo es revelar el mosaico de accesibilidades que el transporte público -ferroviario, metro, tranvía y autobús- confiere a los lugares del Área Metropolitana de Barcelona, dando cuenta de sus atributos de centralidad. Asimismo, se planteará una estrategia de refuerzo de ciertos intercambiadores potenciales de la red ferroviaria en el sentido de activar su capacidad de 
Mercadé Aloy, J., Magrinyà Torner, F., Cervera Alonso de Medina, M. (2020): "Revelando las centralidades del transporte público mediante SIG y GTFS: una propuesta de reequilibrio urbano para el Área Metropolitana de Barcelona", GeoFocus, $n^{\circ} 25$, p. 27-46. http://dx.doi.org/10.21138/GF.657

intermediación y/o de centralidad ${ }^{1}$, como instrumento de mejora del conjunto del sistema de transporte público.

\section{Revisión bibliográfica}

Si bien es cierto que hace décadas, y siglos si se quiere, que las ciudades continúan creciendo, abarcando ámbitos de influencia mayores, la denominada descentralización y su evolución hacia una estructura espacial policéntrica, como la descrita por Hall y Pain (2006), de centros, sub-centros y clústeres de naturaleza muy diversa, son fenómenos relativamente recientes. A pesar de los sucesivos saltos de umbral en relación al desarrollo de los modos de transporte y de las comunicaciones acaecidos desde 1840 en adelante, no es hasta que se generaliza el transporte interurbano en camión, el desarrollo de las terminales suburbanas de ferrocarril y la red viaria especializada, más intensamente después de la segunda guerra mundial, que puede hablarse de una descentralización generalizada (Anas et al., 1998; Antrop, 2004; Hart, 2001; Dupuy, 1991; Herce y Magrinyà, 2002).

En este sentido, las fuerzas de la centralización y descentralización han sido vastamente estudiadas (Batty et al., 2003; Batty et al., 2004). Por un lado, las consecuencias que tendrían sobre la colonización de los espacios abiertos fueron enunciadas de forma premonitoria en el contexto de los EUA (ver, p. ej., Friedmann y Miller,1965) y observadas minuciosamente en el contexto europeo (Indovina, 1990; Font, et al., 1999; Font, 2012; Mangin, 2004). Por otro lado, también se han estudiado desde el punto de vista del planeamiento y construcción de nuevas centralidades ex novo, de carácter más regional, o como instrumento de reequilibro urbano en tejidos existentes en el ámbito más intraurbano (ver, p. ej., Busquets, 1989; Generalitat de Catalunya, 2010).

Paralelamente, la formación de un paisaje de intensidades de concentración urbana irregular a escala regional e intraurbana suscitó y continúa alentando la aparición de modelos explicativos de la estructura espacial de la ciudad de carácter más cuantitativo. Desde el concepto de lugar central del geógrafo Walter Christaller (1966) y del economista August Lösch (1954) y sus derivadas, hasta la necesidad de modelar la ciudad policéntrica (para una revisión ver, p. ej., Anas et al., 1998; Hall, 1997). Interesa, sin embargo, resaltar la importancia de la accesibilidad, que es un ingrediente presente de forma directa o indirecta en dichos modelos, y que se ha consolidado como un concepto esencial en el estudio y planeamiento de la ciudad desde los años 1950s. Batty (2009) ha otorgado a dicho indicador la capacidad de aunar los enfoques morfológicos y funcionales, imprescindibles para la caracterización de la estructura espacial urbana, como han apuntado Bruger y Meijers (2012).

Centrando la atención, pues, en la accesibilidad, debe señalarse que se trata de un concepto difícil de definir y, a su vez, esencial para la confección de estudios urbanos y territoriales (Hanson, 1984). Según Dalvi (1978) la accesibilidad es un indicador que pone de manifiesto la facilidad con la que un determinado lugar puede ser accedido desde una determinada localización, utilizando un determinado medio de transporte. La revisión de la producción científica revela que el

\footnotetext{
1 La intermediación suele utilizarse para referirse a lugares de paso o puertas de acceso, utilizadas para realizar intercambios entre redes, mientras que la centralidad implica necesariamente la noción de lugar central, en el sentido de acumular una determinada masa crítica de actividad (ver, p. ej., Fleming y Hayuth, 1994); sin perjuicio que ciertos lugares puedan concentrar ambos atributos.
} 
Mercadé Aloy, J., Magrinyà Torner, F., Cervera Alonso de Medina, M. (2020): "Revelando las centralidades del transporte público mediante SIG y GTFS: una propuesta de reequilibrio urbano para el Área Metropolitana de Barcelona", GeoFocus, $n^{\circ} 25$, p. 27-46. http://dx.doi.org/10.21138/GF.657

establecimiento de una clasificación de las medidas de accesibilidad ha sido, en sí misma, objeto de análisis por parte de múltiples autores. Resultan especialmente interesantes los esfuerzos realizados en este sentido por parte de Geurs y van Wee (2004) y de Batty (2009), que ofrecen una taxonomía exhaustiva y la identificación de tres grandes categorías respectivamente.

Geurs y van Wee (2004) clasifican los índices de accesibilidad en cuatro grandes grupos, poniendo de relieve sus limitaciones en cada caso: (1) medidas basadas en la infraestructura, (2) medidas basadas en la localización, (3) medidas basadas en la persona y (4) medidas basadas en la utilidad. Los índices centrados en la infraestructura suelen dar cuenta de fenómenos como la congestión o la velocidad comercial, sin incorporar los usos del suelo ni la utilidad. Las medidas basadas en la localización se subdividen en: aquellas en las cuales interviene la distancia o el tiempo de viaje entre los puntos considerados - este es el caso de las medida derivadas, por ejemplo, del concepto de relative accessibility de Ingram (1971)-; las medidas de contorno que contemplan la elección de más de dos posibles destinos a modo, por ejemplo, de contajes de oportunidades para un determinado tiempo de viaje; las medidas de accesibilidad potencial, que también se han denominado gravitacionales, asumiendo la percepción de la persona mediante la distance decay function (ver los estudios de Stewart, 1947; Hansen, 1959; Ingram, 1971; Vickerman, 1974); y los denominados factores de equilibrio de Wilson $(1970,1971)$ que ajustan la magnitud de un determinado flujo (p. ej. los viajes) con la actividad (p. ej. la fuerza de trabajo en el origen y los puestos de trabajo en el destino). Las medidas basadas en la persona, con raíces en la geografía espacio-tiempo de Hagerstrand (1970), se centran en capturar los efectos contextuales, incorporando parámetros tales como las diferencias étnicas o de género. Finalmente, las medidas basadas en la utilidad sitúan el foco en el abanico de alternativas detrás de una determinada decisión a la hora de desplazarse.

Batty (2009) identifica dos elementos relevantes para tratar el concepto de accesibilidad: (1) la escala para la cual se han definido los índices y (2) la diferencia entre medir la accesibilidad en el sentido de evaluar cómo se comportan los usuarios en relación a la actividad económica y social, y cómo reaccionan implícitamente en función de las características físicas de la infraestructura de soporte. Con esta diagnosis, Batty propone un "tipo 1" de accesibilidad que se centraría en el comportamiento en el sentido de dar cuenta de la proximidad de las oportunidades a una determinada zona. Por otro lado, propone una accesibilidad "tipo 2" que asume que las oportunidades son exactamente las mismas en todos los puntos considerados, de manera que aquello que prevalece es la localización y la distancia entre orígenes y destinos, que siempre pueden caracterizarse en base a una determinada impedancia como el tiempo de viaje. Finalmente, todavía identifica un tercer tipo de accesibilidad que suele partir de la aproximación denominada dual ${ }^{2}-$ los segmentos del grafo se convierten en nodos y las intersecciones en arcos-, como en el caso de las formulaciones derivadas de las teorías space syntax ${ }^{3}$ (para un contextualización de las teorías space syntax en el marco de las medidas de centralidad ver, p. ej., Mercadé et al., 2019).

En nuestro caso se quiere abordar la escala del Àrea Metropolitana de Barcelona de una forma simplificada y fácilmente comprensible mediante figuras de tamaño reducido. Ello nos lleva

\footnotetext{
${ }^{2}$ Volchenkov y Blanchard (2008) han descrito la transición hacia un grafo dual como una transformación topológicamente no trivial, que permite encapsular la jerarquía y la estructura de un determinado ámbito urbano que, a su vez, se corresponde con la percepción del espacio que experimenta la gente al desplazarse a través del entorno construido.

${ }^{3}$ Las referencias más relevantes en esta materia pueden encontrarse en los libros de Hillier y Hanson (1984), Hillier (1996) y Hanson (1998), así como en los proceedings de los space syntax Simposia.
} 
Mercadé Aloy, J., Magrinyà Torner, F., Cervera Alonso de Medina, M. (2020): "Revelando las centralidades del transporte público mediante SIG y GTFS: una propuesta de reequilibrio urbano para el Área Metropolitana de Barcelona", GeoFocus, $n^{\circ} 25$, p. 27-46. http://dx.doi.org/10.21138/GF.657

a dejar de lado el factor oportunidad para centrarnos exclusivamente en un planteamiento en el cual las voluntades de relación entre todos los lugares del territorio sean de la misma importancia. En este sentido el conjunto de proyectos de transacción o proyectos transaccionales -voluntad de relación con otros actores/puntos del territorio-, en la terminología de Dupuy (1991), se extenderían a su totalidad. Se trata, por lo tanto, de una aproximación que nos sitúa directamente en las medidas basadas en la localización de Geurs y van Wee (2009) y en el tipo 2 o 3 de Batty (2009), donde el factor oportunidad/comportamiento queda excluido o únicamente se analiza implícitamente por la propia configuración espacial de la estructura urbana.

Existen, a su vez, múltiples planteamientos que renuncian directamente al factor oportunidad. Suelen destacarse en este sentido las denominadas medidas de centralidad -se centran mayoritariamente en la topología dejando de lado, generalmente, el tiempo de viaje- que derivan de la propia teoría de grafos (Garrison, 1960; Kansky, 1963; Haggett y Chorley, 1969; Hillier and Hanson, 1984) y de la sociología estructural (Porta et al., 2006; Freeman 1977). El caso de space syntax se incluye en este conjunto de planteamientos y en la categoría 3 identificada por Batty (2009).

En nuestro caso, sin embargo, se quiere centrar la atención en las redes de transporte público donde el factor tiempo de viaje resulta esencial para caracterizar la fricción disimilar que se experimenta al desplazarse en función de los orígenes y destinos que se consideren. Y, como se ha expuesto en la introducción, también se quiere dar cuenta de las vocaciones de centro de los nodos en función de su accesibilidad. En este sentido, se apuesta por la visualización de curvas isócronas de accesibilidad -el lugar geométrico de los puntos que se encuentran a una determinada distancia temporal respecto de otro $\mathrm{u}$ otros puntos (para una revisión de la utilidad y formas de expresar las isócronas de accesibilidad ver Allen, 2019). Concretamente, se tomará como referencia el concepto de integral accessibility de Ingram (1971), que permite calcular la accesibilidad de cada origen respecto de todos los destinos que se consideren, dando cuenta del valor de posición de cada lugar en el sino de un determinado ámbito. Este planteamiento quedaría comprendido en el denominado tipo 2 de accesibilidad de Batty (2009) y se trataría de una medida basada en la localizacióndistancia según la clasificación de Geurs y van Wee (2004).

O’Sullivan et al. (2000) sitúan los orígenes de los mapas de isócronas de accesibilidad en los ejemplos de los años 1932, 1938 y 1939 identificados per Momkhouse y Wilkinson (1971) y los estudios de planificación del transporte de los años 1950s (Kok 1951, Rowe 1953); por bien que, en realidad, existen ejemplos anteriores, como es el caso del "Isochronic passage Chart" realizado por Galton (1881) a finales del XIX. En el caso del Área Metroplitana de Barcelona, destacan los trabajos de Herce (2005) - utiliza las isócronas de accesibilidad para dar cuenta del incremento generalizado de la accesibilidad después de los acontecimientos olímpicos de 1992, que conllevaron la alteración del precio del suelo y de los patrones de localización de la actividad- y la contribución de Gómez y de Solà-Morales (1971).

Con todo, nos situamos en el campo de la isoaccesibilidad, deducible, en una primera aproximación, a partir de la propia geometría -el grafo de nodos y arcos- de las redes de transporte público. El establecimiento de su configuración espacial -estaciones/paradas e infraestructura/itinerarios-, a partir de la cartografía disponible, puede resultar relativamente sencillo para la red ferroviaria y mucho más complejo para las redes del autobús. Pero la caracterización de las impedancias del conjunto resulta todavía más difícil de modelar. Idealmente se deberían tener en cuenta los horarios de las distintas expediciones así como los tiempos a pie 
Mercadé Aloy, J., Magrinyà Torner, F., Cervera Alonso de Medina, M. (2020): "Revelando las centralidades del transporte público mediante SIG y GTFS: una propuesta de reequilibrio urbano para el Área Metropolitana de Barcelona", GeoFocus, $n^{\circ} 25$, p. 27-46. http://dx.doi.org/10.21138/GF.657

entre paradas y estaciones. Afortunadamente, existe el formato común General Transit Feed Specification (GTFS) que permite tener en cuenta las frecuencias de las expediciones del transporte público de forma georeferenciada para cada ruta ofertada. El GTFS representa, entre otros elementos, las expediciones, los horarios, las rutas y las paradas o estaciones en un formato tipo texto comprimido que puede ser interpretado per un SIG. Inicialmente fue desarrollado por TriMet y Google (2005), tomando el nombre de Google Transit Feed Specification (GTFS), que se sustituyó en el año 2010 por el de General Transit Feed Specification (ver, p. ej., McHugh, 2013).

Existen múltiples estudios realizados a partir del uso del formato GTFS. Hadas (2013) ha planteado un conjunto de indicadores de conectividad para las ciudades de Auckland, Vancouver y Portland. Fayyaz et al. (2017), a partir de la información GTFS, han desarrollado un algoritmo open-source para el manejo de la información GTFS y lo han implementado en la ciudad de St. George (Utah) para cada estación, considerando el tiempo de viaje y las oportunidades en las destinaciones. Goliszek y Polom (2016) han utilizado GTFS para evaluar desviaciones en el funcionamiento de transporte público desde el centro de la ciudad de Stettin. En el caso del Área Metropolitana de Barcelona es destacable la contribución del equipo de redacción del Plan Director Urbanístico (AMB, 2018), que supone una variación de la metodología PTAL (Kerrigan y Bull, 1992), introduciendo factores de utilidad.

Centrando finalmente la atención en el Área Metropolitana de Barcelona y en el objetivo de este artículo, debe señalarse que durante los últimos 30 años las redes que más se han extendido han sido la red viaria de alta capacidad y el ferrocarril de alta velocidad. En este sentido se ha identificado la necesidad de un cambio de tendencia en la inversión en infraestructuras de transporte que priorice claramente el transporte público de proximidad, para reequilibrar el reparto modal actual (ver, p. ej., Magrinyà, 2019). El Plan de Movilidad Urbana de Barcelona establece, en este sentido, el objetivo de reducir el vehículo privado hasta un $20 \%$, cifra que muy bien pudiera adoptarse, también, en el Plan Metropolitano de Movilidad Urbana del Área Metropolitana de Barcelona (AMB), actualmente en redacción. Los datos recogidos en el documento "Transició a la Mobilitat sostenible de l'AMB" (AMB, 2017) dibujan el siguiente reparto modal, transporte público/vehículo privado, en función del tipo de interacción que se considere: (1) $63 \% / 37 \%$ para los desplazamientos intraurbanos en Barcelona, (2) $52 \% / 48 \%$ para los desplazamientos de conexión entre Barcelona y las ciudades con red de metro o tranvía y (3) $42 \%$ y $58 \%$ para los desplazamientos de conexión entre Barcelona y las ciudades que no disponen de red de metro o tranvía. Es evidente que la implementación de medidas y políticas efectivas para la consecución de este tipo de objetivos supone una tarea muy compleja. Banister (2008) ha puesto de manifiesto la insuficiencia de la mera disponibilidad de un haz de medidas en este sentido, señalando que es imprescindible la confianza y aceptabilidad por parte de los actores implicados y de la ciudadanía en general mediante su participación activa entre otros aspectos. Nuestra aproximación, en cualquier caso, no permite trabajar desde dicha complejidad, y se centra en la aportación de la accesibilidad como instrumento de lectura y de propuesta. 
Mercadé Aloy, J., Magrinyà Torner, F., Cervera Alonso de Medina, M. (2020): "Revelando las centralidades del transporte público mediante SIG y GTFS: una propuesta de reequilibrio urbano para el Área Metropolitana de Barcelona", GeoFocus, $n^{\circ} 25$, p. 27-46. http://dx.doi.org/10.21138/GF.657

\section{Materiales, datos y métodos}

\subsection{Caso de estudio y datos}

El caso de estudio propuesto es el Área Metropolitana de Barcelona, integrada por 36 municipios con una población en torno a los tres millones de habitantes (Área Metropolitana de Barcelona, n.d.).

Los datos que se han utilizado son básicamente los GTFS de 2017 de las compañías y operadores de transporte público correspondientes: Área Metropolitana de Barcelona (Authosa, Mohn. Sl, Oliveras. S1, Rosanbus. S1, Soler i Sauret, Sgmt, TCC, Tusgsal, UTE línia 88); BUS (Sarbus, Sarbus - moventis, Ajuntament de Pallejà, C. M. de Gestió de Fontpine, Autos Castellbisbal SA, ValldoreixBUS, ALSA); Ferrocarrils de la Generalitat de Catalunya; Generalitat de Catalunya (Autocares); RENFE Cercanías; TMB (incluye la red de metro y bus de Barcelona); y TRAM (red de tranvía). El contenido básico de los GTFS incluye las tablas agency, routes, trips, stop_times, stops y claendar. Agency contiene los datos de la agencia de transporte que facilita la información GTFS. Stops contiene la información individualizada de cada parada y/o estación de la red, esencialmente su geolocalización. Routes contiene las rutas: el conjunto de viajes que se ofrecen al usuario como un único servicio. Trips contiene las secuencias de dos o más paradas para cada ruta. Stop times contiene la hora de llegada y salida de cada vehículo para cada secuencia -trips- y cada ruta. Finalmente, calendar contiene los intervalos de días de servicio, pudiéndose distinguir entre días laborables y fines de semana entre otras singularidades. En nuestro caso se usa la información contenida en todas las tablas.

Complementariamente, se utiliza la Base Municipal y la red viaria de la Base Cartográfica 1:25.000, elaboradas por el Institut Cartogràfic i Geològic de Catalunya (ICGC); así como los mapas vectoriales de la Clasificación del suelo en formato shapefile, que conforman el Mapa urbanístico de Catalunya (MUC), elaborado por el departamento de Territori $i$ sostenibilitat de la Generalitat de Catalunya. El mapa urbanístico se utiliza para poder restringir los orígenes y destinos al suelo urbano, como se desarrolla en el apartado siguiente.

\subsection{Técnicas de análisis.}

El conjunto de técnicas de análisis espacial centran su atención en: la definición de los orígenes y destinos a considerar, la formulación de la medida de accesibilidad adecuada, la representación de las curvas isócronas de accesibilidad y la edición de los GTFS para construir escenarios de mejora.

Para establecer la matriz de orígenes y destinos que ha de almacenar los tiempos asociados a los desplazamientos se plantea la construcción de una malla ortogonal de puntos que equidistan $500 \mathrm{~m}$ entre ellos (véase figura 1). Dichos puntos ocuparan solamente los ámbitos del suelo clasificado como urbano, de manera que se descartan los espacios abiertos embebidos en el mosaico metropolitano. Se asume, pues, que las oportunidades son exactamente las mismas en todos los puntos que se consideran, que actúan simultáneamente de origen y destinos. Este planteamiento, muy simplificado, entronca claramente con el tipo " 2 " de accesibilidad considerado por Batty (2009) y se trataría de una medida basada en la localización-distancia a partir de la clasificación de Geurs y van Wee (2004). 
Mercadé Aloy, J., Magrinyà Torner, F., Cervera Alonso de Medina, M. (2020): "Revelando las centralidades del transporte público mediante SIG y GTFS: una propuesta de reequilibrio urbano para el Área Metropolitana de Barcelona", GeoFocus, $n^{\circ} 25$, p. 27-46. http://dx.doi.org/10.21138/GF.657

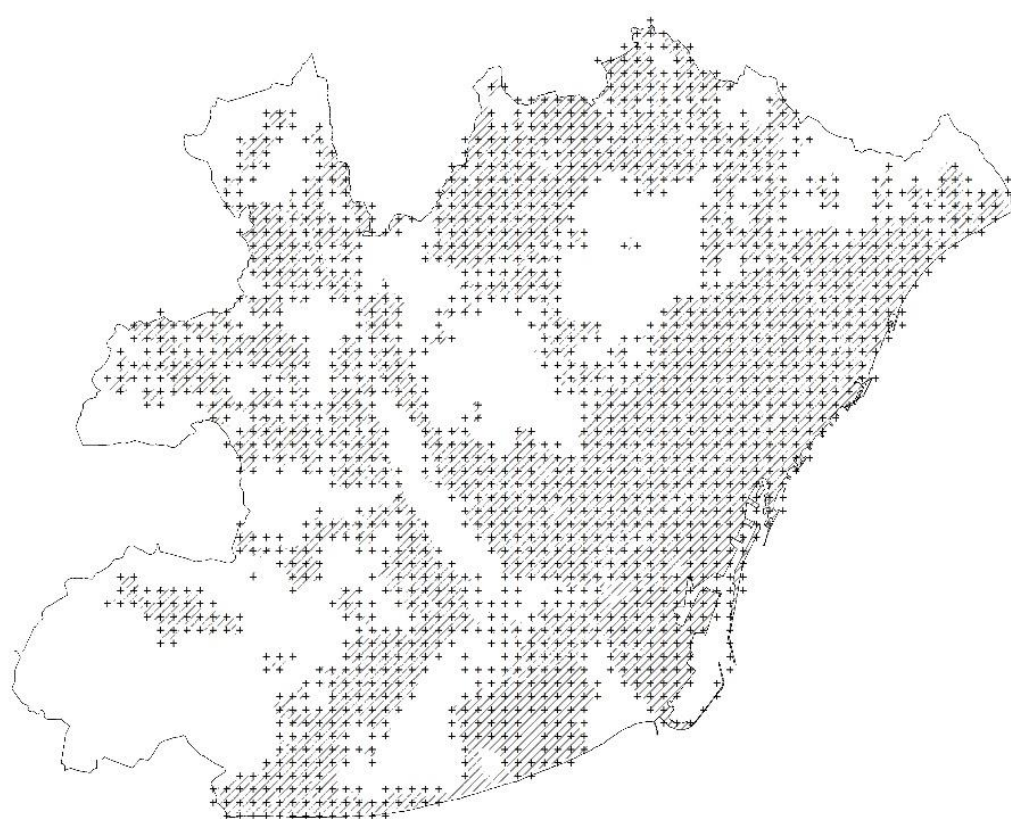

Figura 1. Orígenes y destinos.

Elaboración propia

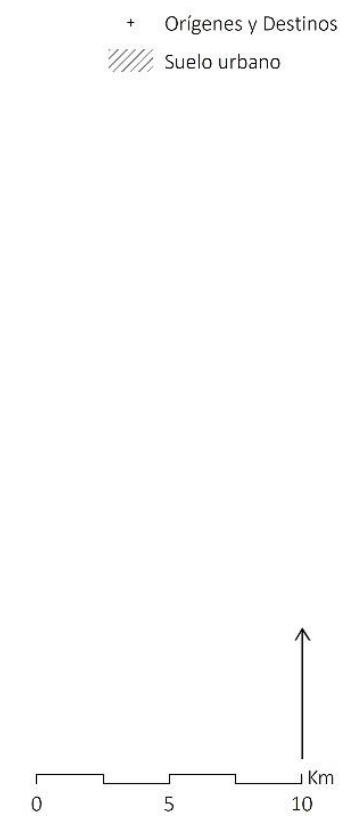

0

La medida de accesibilidad que se considera es la denominada integral accessibility (Ingram, 1971). Ingram (1971) define la relative accessibility como el grado de conexión de dos lugares (nodos) en una misma superficie, siendo éste no necesariamente simétrico -téngase, por ejemplo, en cuenta el caso de calles de sentido único. A continuación, se define el concepto de accesibilidad integral para un determinado nodo como una función escalar de las accesibilidades relativas a dicho punto. En nuestro caso, para la accesibilidad relativa se tomará el camino mínimo en base a la impedancia que supone el tiempo de viaje. En el caso de la accesibilidad integral se considerará, para cada origen, el promedio de todos los valores de accesibilidad relativa de dicho origen con todos los destinos. La accesibilidad integral de Ingram (1971) se ha denominado, también, absoluta por otros autores (Monzón de Cáceres, 1988; Calvo et al., 1993).

$A_{i}$ : Accesibilidad integral del nodo $i$

$$
A_{i}=\frac{1}{N-1} \sum_{j=1, j \neq i}^{N-1} d_{i j}
$$

$N$ : Número total de nodos

$d_{i j}$ : Tiempo de viaje entre $i$ y $j$ por el camino mínimo

Se sabe, a priori, que este tipo de índice de accesibilidad conlleva una dependencia espacial importante, en el sentido de privilegiar aquellos lugares situados en el centro del grafo. Este efecto se puede observar claramente, por ejemplo, en el trabajo de López-Escolano, et al. (2016) al comparar los resultados que se obtienen para la red viaria en la España peninsular con: (1) la accesibilidad absoluta potencial y (2) la introducción del llamado factor de ruta (para una revisión de estos conceptos ver, p. ej., Monzón de Cáceres, 1988; Calvo et al., 1993). En el primer caso se obtiene un patrón de decaimiento de valores desde un centro de gravedad situado de forma central- 
Mercadé Aloy, J., Magrinyà Torner, F., Cervera Alonso de Medina, M. (2020): "Revelando las centralidades del transporte público mediante SIG y GTFS: una propuesta de reequilibrio urbano para el Área Metropolitana de Barcelona", GeoFocus, $n^{\circ} 25$, p. 27-46. http://dx.doi.org/10.21138/GF.657

septentrional en la península, de manera que los lugares más alejados registran valores progresivamente inferiores. En cambio, con el factor de ruta, que resalta aquellas relaciones cuyo itinerario mínimo para el tiempo de viaje coincide con el itinerario de menor distancia, se obtiene un paisaje de accesibilidades totalmente distinto, dando cuenta de la calidad de la comunicación entre nodos. En este segundo caso, los valores que se obtienen dibujan los corredores de mayor peso en el territorio, diluyendo el esquema concéntrico que se obtiene con la accesibilidad absoluta. En nuestro caso existen dos razones para no considerar esta relación entre camino mínimo para el tiempo de viaje y camino de distancia mínima. En primer lugar, se ha planteado una malla de orígenes y destinos de 500x500m, a modo de píxeles de la mancha de suelo urbano. Por lo tanto, dichos nodos no se corresponden con lugares reales y en un cierto entorno de cada punto no existe suficiente distancia entre ellos como para que tome sentido la doble lectura tiempo-distancia. En segundo lugar, los GTFS que se han utilizado no incluyen, en la mayoría de los casos, el elemento denominado shape que permite obtener el eje de la ruta en cada caso.

La elaboración de las matrices de orígenes y destinos, cuyos coeficientes serán poblados por los valores de la accesibilidad relativa en cada caso, se realiza mediante el módulo de análisis de redes del software ESRI ArcMap 10.6 (C) (ESRI, n.d.). El cálculo específico de cada tiempo de viaje se realiza mediante la herramienta Add GTFS to a Network Dataset (ESRI, n.d.), que permite establecer el grafo como combinación de los GTFS del transporte público y conectar dicho grafo con la red viaria de soporte. En este sentido, debe señalarse que se descartan otras alternativas como la API de Google Maps por la necesidad de editar los GTFS para la simulación de escenarios de mejora.

Para la construcción del grafo, en nuestro caso, se utiliza el conjunto de GTFS que se ha expuesto en el apartado dedicado a los datos. La relación entre las paradas y estaciones con la red viaria se establece por proximidad -se realiza una proyección del nodo hacia el arco de calle más cercano-, de manera que se añade una demora de entrada y de salida de 30 y 15 segundos respectivamente, así como una velocidad a pie de $4,83 \mathrm{~km} / \mathrm{h}$. Los propios GTFS ya almacenan el resto de impedancias asociadas a los arcos de las rutas de transporte. Los cálculos que se van a realizar son, en realidad, los caminos mínimos entre cualesquiera dos puntos, utilizando el algoritmo de Dijkstra (para una revisión de algoritmos de camino mínimo ver, p. ej., Cherkassky et al., 1996). El uso de los GTFS obliga a establecer una fecha y hora concreta para realizar los cálculos a partir de los orígenes considerados. En nuestro caso se consideran las 8h del 02/03/2017, que es un día laborable comprendido en el intervalo de vigencia de los GTFS disponibles.

Complementariamente, debe considerarse un método de edición y modificación de GTFS para elaborar escenarios de mejora. En nuestro caso se utiliza una herramienta basada en Excel (Microsoft Office), elaborada por Heitzman (n.d.).

Finalmente hay que plantear la forma de representación gráfica de las isócronas de accesibilidad. En nuestro caso, el propio planteamiento -la consideración de una malla ortogonal de orígenes y destinos y el uso de los GTFS - obliga a generar la nueva cartografía a partir de la información que almacenen los nodos de origen. Allen (2019), ha identificado dos formas tradicionales, basadas en el área, de expresar las isócronas: la isolíneas y los polígonos concéntricos. Por otro lado, ha puesto en evidencia la posibilidad de expresar los rangos de valores mediante los propios segmentos de red viaria -arcos entre intersecciones-, en una expresión de tipo dual, afín a los planteamientos space syntax, en el sentido que se ha expresado en el apartado de revisión de literatura. En el primer caso -expresión basada en el área- es necesario realizar una interpolación 
Mercadé Aloy, J., Magrinyà Torner, F., Cervera Alonso de Medina, M. (2020): "Revelando las centralidades del transporte público mediante SIG y GTFS: una propuesta de reequilibrio urbano para el Área Metropolitana de Barcelona", GeoFocus, $n^{\circ} 25$, p. 27-46. http://dx.doi.org/10.21138/GF.657

entre los valores obtenidos para los nodos que actúan de orígenes. En el segundo caso -expresión basada en la red- dicha interpolación pudiera realizarse considerando el desplazamiento real necesario a realizar por la red de calles hasta llegar al nodo considerado origen. En nuestro caso, se pretende una escala de análisis gruesa, que pueda expresarse mediante figuras de dimensiones convencionales para todo el Área Metropolitana de Barcelona. Se opta, pues, por una triangulación de los valores obtenidos en cada origen, que supone la construcción de una red irregular de triángulos (TIN) como paso previo a la obtención de isolíneas de accesibilidad. Ello se realiza, también, mediante el software ESRI ArcMap 10.6 ○.

\section{Descripción y análisis de resultados}

En este apartado se analiza el escenario actual -los GTFS disponibles son del año 2017-y se describe y analiza un escenario de mejora, en relación a los niveles de accesibilidad y centralidad potencial que se obtienen. Debe recordarse que la aproximación metodológica que se plantea explora únicamente la aportación del ingrediente accesibilidad como componente del concepto de centralidad $^{4}$. La figura 2 muestra el mapa de la red ferroviaria con las estaciones existentes, la nube de paradas de autobús existentes, los nodos que intervienen en el escenario mejorado y la nomenclatura que se utilizará para referirse a los ejes de infraestructura principales.

El primer resultado que debe obtenerse, pues, es el escenario de accesibilidades inicial, que se muestra en la figura 3, mediante las isócronas de accesibilidad integral para rangos de valores expresados en minutos. La mera observación de la rampa de colores obtenida revela un centro Barcelona- privilegiado, que se sitúa por debajo de los 55 minutos de tiempo de viaje, y unos ejes de penetración hacia la región que confieren accesibilidad: (1) C-58 - C-58/ C-33; (2) A-2 - B-23 AP-7; (3) C-32; (4) C-16. En el caso del "centro" observado en Barcelona, se ilumina un recinto especialmente privilegiado entre Av. Diagonal, Psg. de St. Joan, Psg. de Colom, Av. Paral.lel y Gran Via de Carles III. Fuera de dicho recinto cabe mencionar un cierto archipiélago de lugares que se presentan como centrales de manera más aislada, en el propio continuo urbano: el área en torno al intercambiador de la Torrassa y el ámbito comprendido entre las estaciones de Plaza Europa y de Idelfons Cerdà esencialmente.

Para el escenario mejorado, se plantea una estrategia de refuerzo de ciertos intercambiadores potenciales de la red ferroviaria en el sentido, como se ha dicho, de activar su capacidad de intermediación y/o de centralidad. La mera observación aislada de la red ferroviaria, compuesta por las redes de bus, tranvía, Metro, Ferrocarrils de la Generalitat de Catalunya y Cercanías de RENFE, permite la identificación de ciertos lugares de intercambio, que se encuentran infrautilizados. Se detectan las siguientes oportunidades: (1) permitir el intercambio de la líneas de Metro L1 y L9 con las líneas R3 y R4 de RENFE cercanías en la Torrassa; (2) permitir el intercambio de la línea L1 de Metro con las R3 y R4 de RENFE cercanías en la estación de Glòries; (3) generar una nueva estación en Riu Sec, de manera que se pueda realizar el intercambio entre la R4 y la R8 de RENFE cercanías; y (4) generar un bypass en Montcada Bifurcació, que permita el intercambio con la R2 de RENFE cercanías (véase figura 2).

\footnotetext{
${ }^{4}$ La noción de centralidad, en el marco de una configuración espacial policéntrica, implica necesariamente la evaluación relativa de las dimensiones morfológicas - la distribución equilibrada de centros y subcentros- y funcionales -las relaciones entre los centros- de los lugares objeto de estudio (ver p. ej. Burger y Miejers, 2012). En nuestro caso únicamente se explora la vertiente funcional parcialmente, mediante la accesibilidad, en el sentido expresado en el apartado 3 en relación a los materiales, datos y métodos.
} 


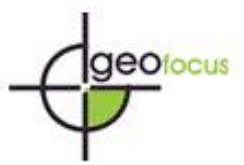

Mercadé Aloy, J., Magrinyà Torner, F., Cervera Alonso de Medina, M. (2020): "Revelando las centralidades del transporte público mediante SIG y GTFS: una propuesta de reequilibrio urbano para el Área Metropolitana de Barcelona", GeoFocus, $n^{\circ} 25$, p. 27-46. http://dx.doi.org/10.21138/GF.657

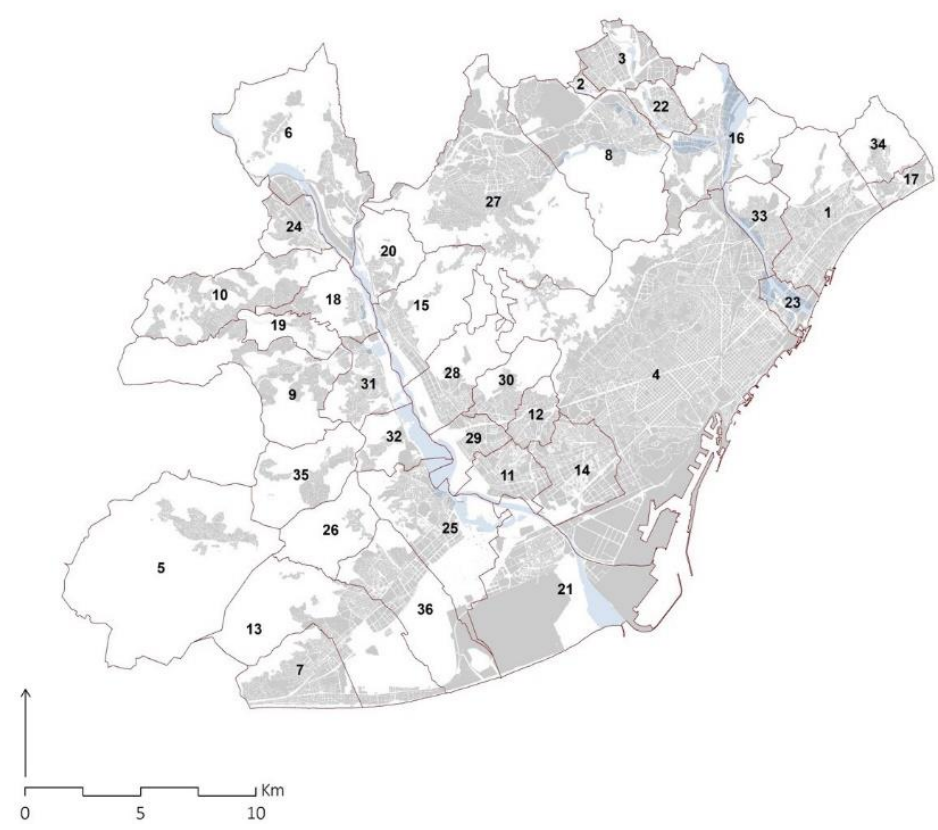

1, Badalona

2, Badia del Vallès

3, Barberà del Vallès

4, Barcelona

6, Begues

7. Castelldefels

8 , Cerdanyola del Valles

9, Cervelló

10, Corbera de Llobregat

11, Cornellà de Llobregat

12 , Esplugues de Llobregat

13, Gavà

14, l'Hospitalet de Llobregat

15 , Molins de Rei

16, Montcada i Reixac

17, Montgat

18, Pallejà

19, la Palma de Cervelló

20, el Papiol

21, el Prat de Llobregat

22, Ripollet

23, Sant Adrià de Besòs

24, Sant Andreu de la Barca

25, Sant Boide Hlobrect

26, Sant Climent de Llobregat

27 , Sant Cugat del Vallès

28, Sant Feliu de Llobregat

29, Sant Joan Despí

30, Sant Just Desvern

31, Sant Vicenç dels Horts

32, Santa Coloma de Cervelló

33, Santa Coloma de Gramenet

34, Tiana

35 . Torrelles de Llobregat

(a)

36 , Viladecan

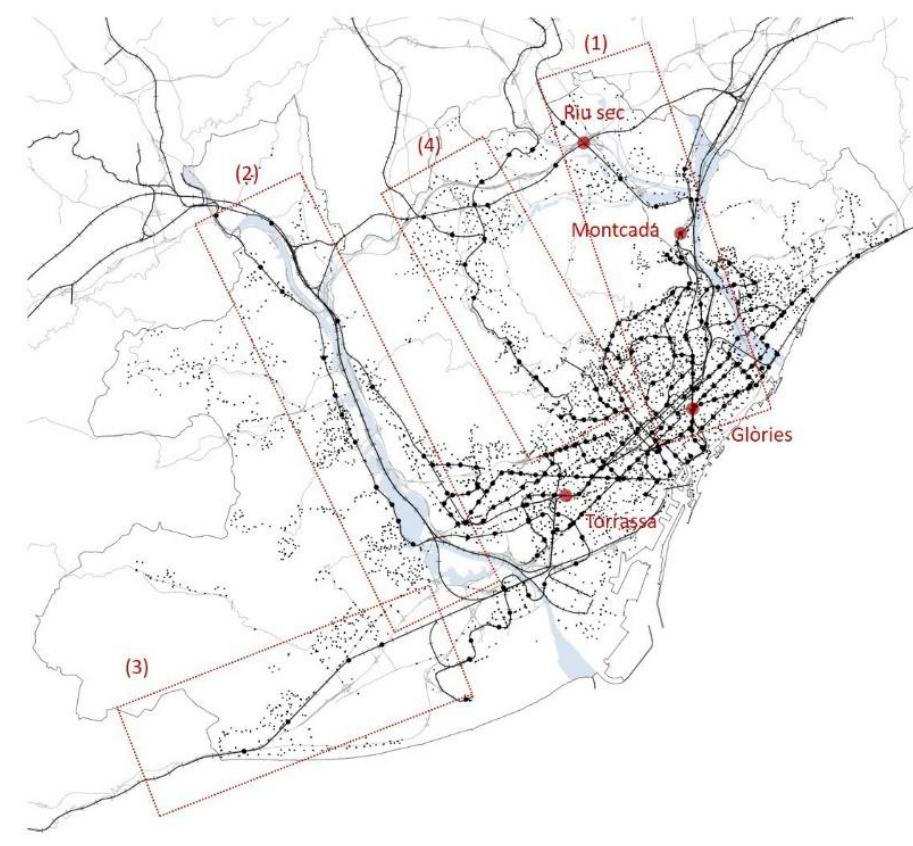

- Nodos nuevos o alterados

$\longrightarrow$ Red Ferroviaria

Red viaria

- Estación Ferroviaria existente

Parada Bus existente

Ejes

(1) $\mathrm{C}-58-\mathrm{C}-58 / \mathrm{C}-33$

(2) $\mathrm{A}-2-\mathrm{B}-23-\mathrm{AP}-7$

(3) $\mathrm{C}-32$

(4) C-16

(b)

Figura 2. Encaje territorial y propuesta de escenario mejorado: a) municipios del Área Metropolitana de Barcelona, b) escenario mejorado (1), Torrassa, Riu Sec, Glòries-Clot, bypass Montcada

Elaboración propia

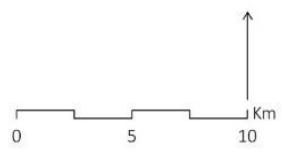


Mercadé Aloy, J., Magrinyà Torner, F., Cervera Alonso de Medina, M. (2020): "Revelando las centralidades del transporte público mediante SIG y GTFS: una propuesta de reequilibrio urbano para el Área Metropolitana de Barcelona", GeoFocus, $n^{\circ} 25$, p. 27-46. http://dx.doi.org/10.21138/GF.657

A continuación, se realiza el mismo cálculo para el escenario modificado a partir de la edición de los GTFS disponibles (véase figura 4). Y, finalmente, se realiza la diferencia entre ambos escenarios para dar cuenta de la alteración que conllevan las mejoras propuestas (véase figura 5).

Los resultados obtenidos permiten observar mejoras significativas en el entorno de la estación de Riu Sec, que, a su vez, suponen un decremento del tiempo de viaje en Barberà del Vallès, Badia del Vallès, la Universitat Autònoma de Barcelona (UAB) y Cerdanyola del Vallès. Por otro lado, se observan mejoras en los cuatro cuadrantes del encuentro entre el eje viario Ronda del Litoral - C-58/C-33 y la B-20 que privilegian un cierto mosaico de localizaciones: Las Roquetes en el cuadrante noroeste; el entorno de la Maquinista, el extremo norte de la Rambla de Prim, el entorno de las estaciones del Clot y Glòries, el entorno de la Av. Diagonal entre la calle Bilbao y la calle Bac de Roda, el sudoeste del Besós, la Mina y Diagonal Mar en el cuadrante sudoeste; Santa Coloma de Gramenet en el entorno del eje Rambla de Sant Sebastià, Nova Lloreda, Sistrells, Can Claris y el polígono de Montigalà en Badalona; así como Sant Adrià del Besós en el cuadrante sudeste. En relación al eje A-2 - B-23 - AP-7, se observan mejoras en Castellbisbal, El Papiol, Molins de Rei, Sant Feliu de Llobregat y Sant Joan Despí. Finalmente, en torno al eje C-32, puede hablarse de mejoras generalizadas en Castelldefels, Gavà y Viladecans.

En general, pues, se observa el refuerzo de los ejes (1) “C-58 - C-58/C-33”, (2) l'eix "A-2 B-23 - AP-7" y (3) C-32, así como el mantenimiento, e incluso el ligero decremento, del estatus del eje (4) C-16 (véase una referencia a los ejes en la figura 2).

Finalmente, desde una óptica municipal y más cuantitativa, se realiza una estadística zonal para establecer el valor medio y máximo de mejora entre todos los orígenes considerados para cada municipio. La figura 6 recoge dichos resultados, revelando una mayor concentración de las mejoras en: Cerdanyola del Vallès, Castellbisbal, el Papiol, Cervelló y Sant Joan Despí. Y, en menor medida, se registran mejoras en: Badia del Vallès, Barberà del Vallès, Ripollet, Montcada i Reixach, Sant Feliu de Llobregat, Corbera de Llobregat, la Palma de Cervelló, Gavà y Castelldefels. No existe una correlación específica entre los lugares menos privilegiados inicialmente y la concentración de mejoras, si bien también es cierto que se observa un claro reequilibrio que concentra los beneficios fuera de la ciudad de Barcelona. 


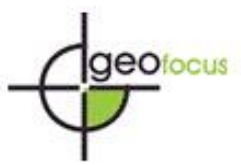

Mercadé Aloy, J., Magrinyà Torner, F., Cervera Alonso de Medina, M. (2020): "Revelando las centralidades del transporte público mediante SIG y GTFS: una propuesta de reequilibrio urbano para el Área Metropolitana de Barcelona", GeoFocus, $n^{\circ} 25$, p. 27-46. http://dx.doi.org/10.21138/GF.657
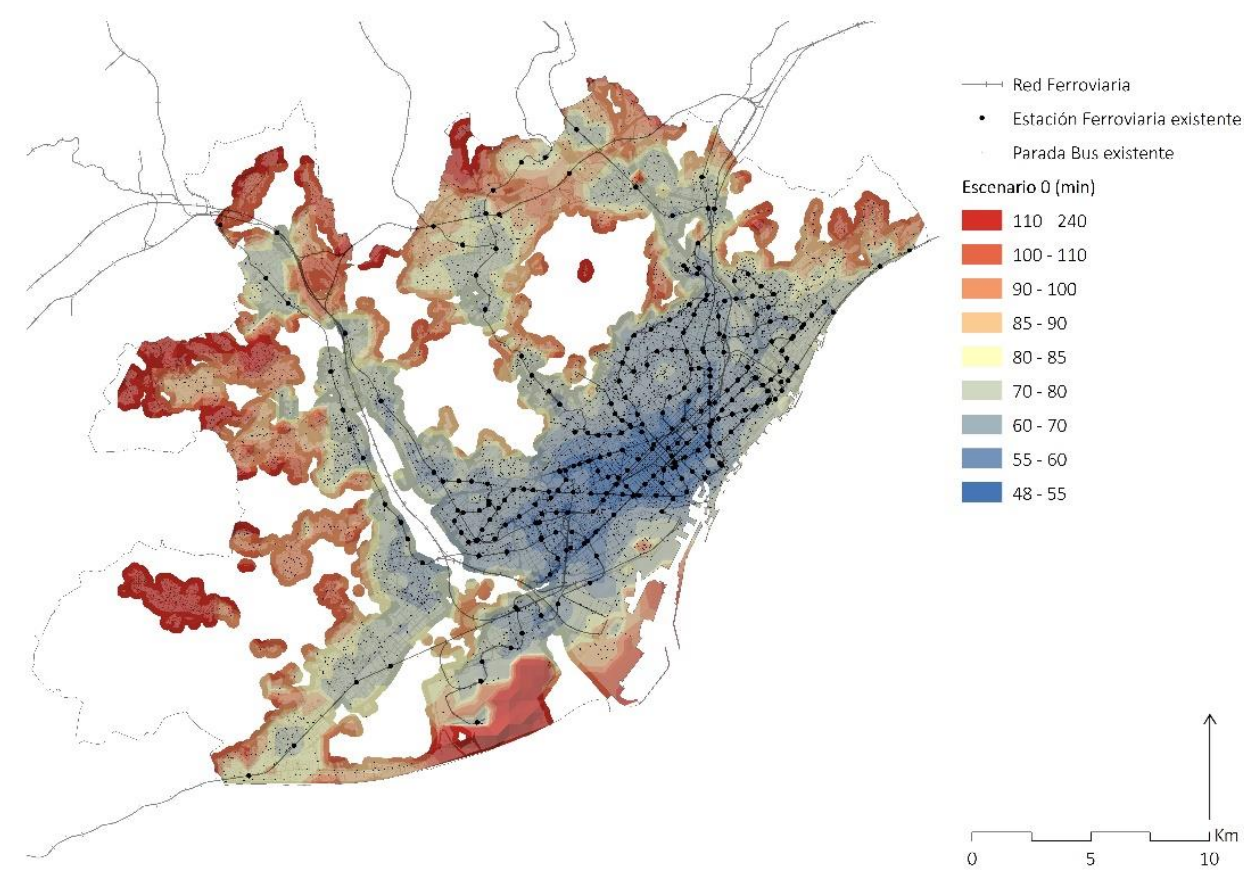

Figura 3. Isócronas de accesibilidad en minutos para el escenario actual (0) Elaboración propia
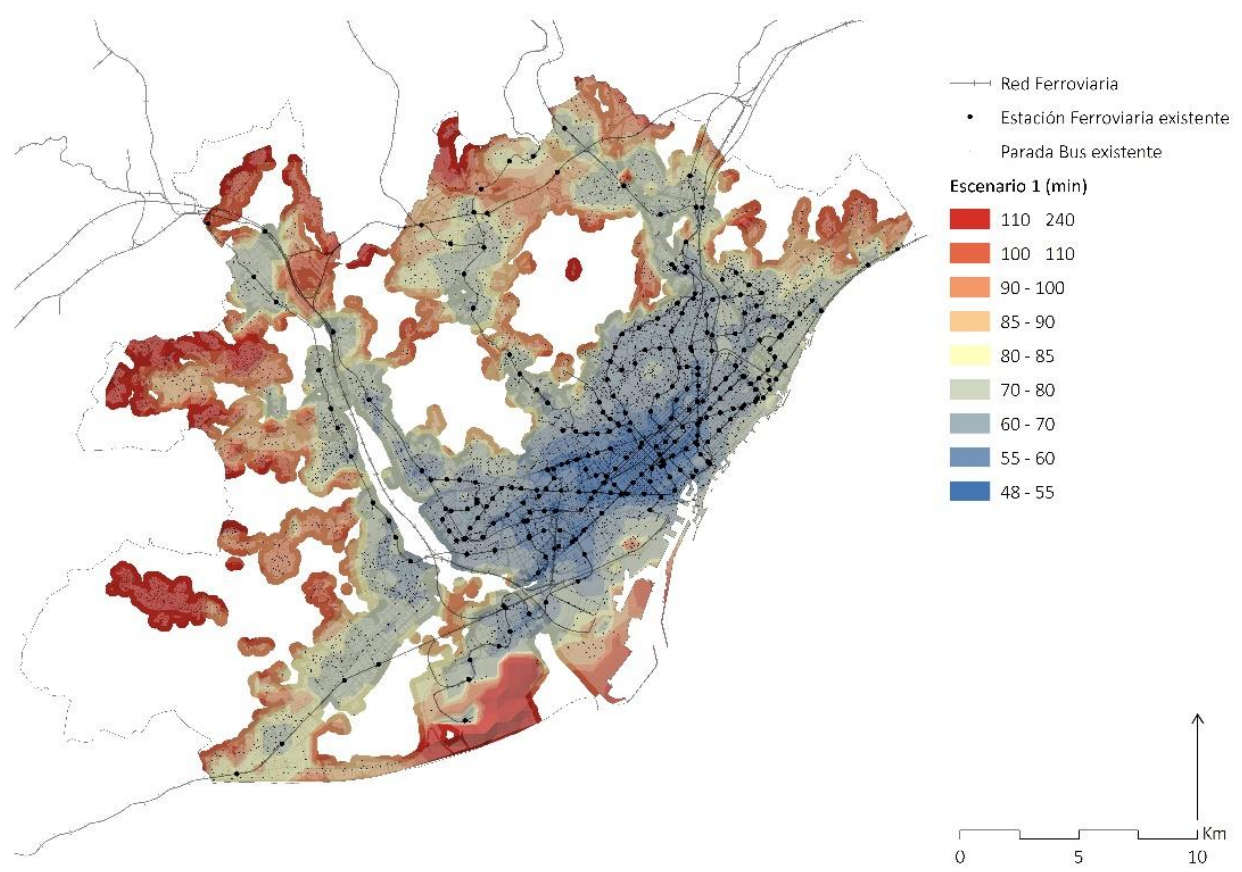

Figura 4. Isócronas de accesibilidad del escenario mejorado (1). Torrassa, Riu Sec, GlòriesClot, bypass Montcada

Elaboración propia 


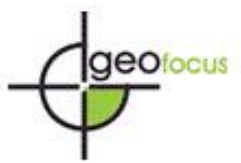

Mercadé Aloy, J., Magrinyà Torner, F., Cervera Alonso de Medina, M. (2020): "Revelando las centralidades del transporte público mediante SIG y GTFS: una propuesta de reequilibrio urbano para el Área Metropolitana de Barcelona", GeoFocus, $n^{\circ} 25$, p. 27-46. http://dx.doi.org/10.21138/GF.657

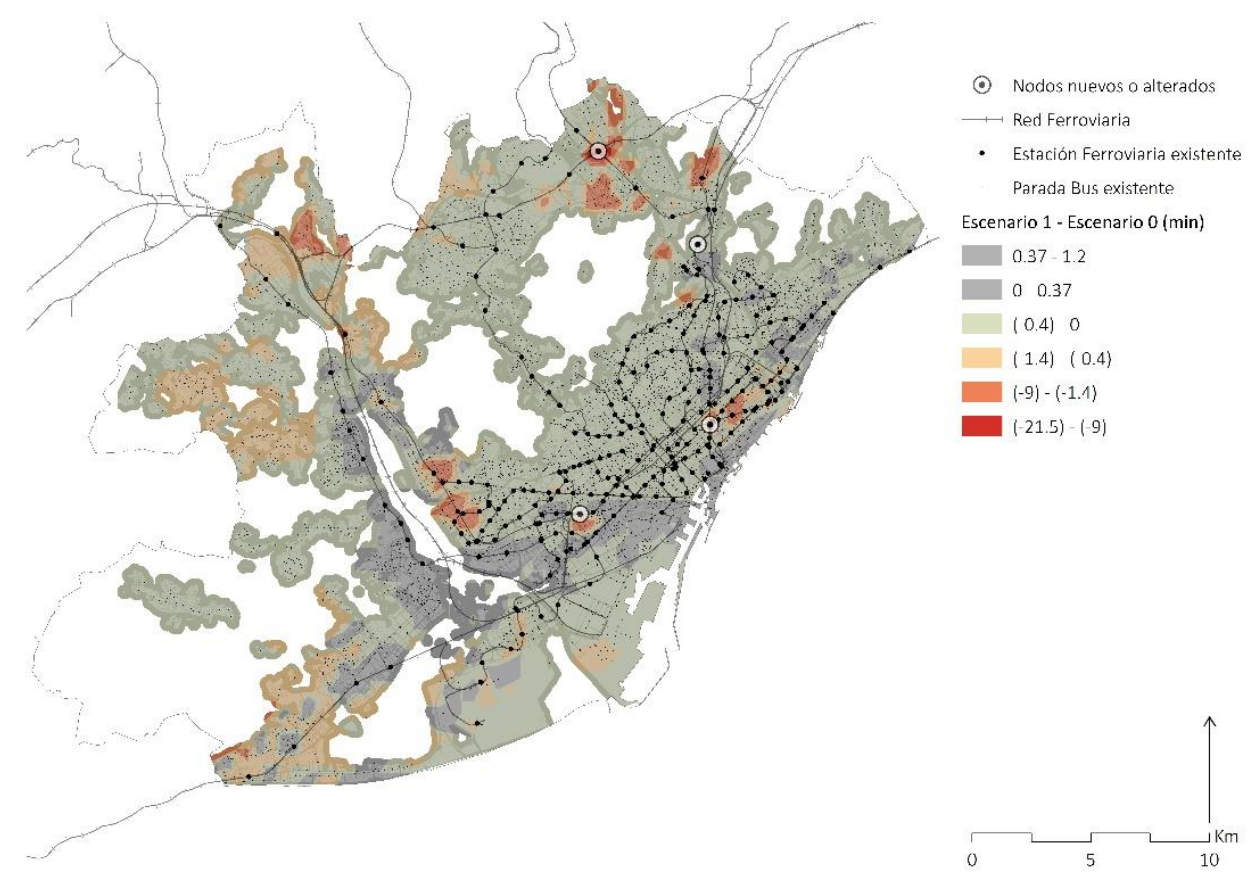

Figura 5. Isócronas de accesibilidad de la diferencia entre el escenario (1) y el escenario (0). Elaboración propia

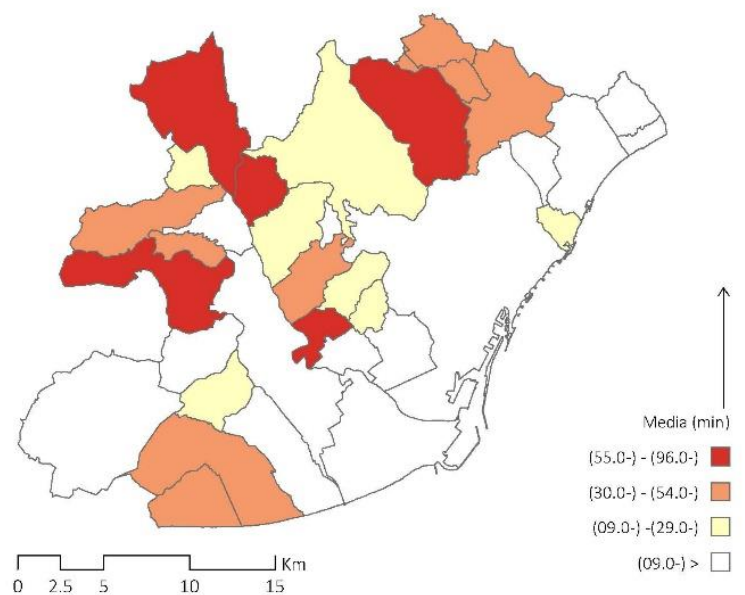

(a)

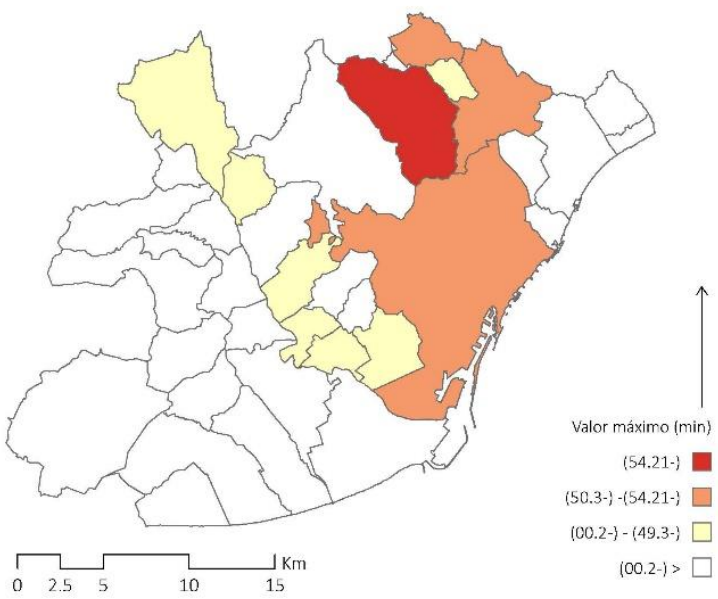

(b)

Figura 6. Valores de accesibilidad de la diferencia entre el escenario (1) y el escenario (0) por municipios: (a) media, (b) valor máximo

Elaboración propia 
Mercadé Aloy, J., Magrinyà Torner, F., Cervera Alonso de Medina, M. (2020): "Revelando las centralidades del transporte público mediante SIG y GTFS: una propuesta de reequilibrio urbano para el Área Metropolitana de Barcelona", GeoFocus, $n^{\circ} 25$, p. 27-46. http://dx.doi.org/10.21138/GF.657

\section{Discusión y valoración de hallazgos}

La discusión de los resultados se centra en la aportación aislada de los valores de accesibilidad con transporte público obtenidos. En este sentido se puede, sin embargo, centrar la atención en las alteraciones y mejoras que han supuesto los refuerzos nodales propuestos, dejando de lado la valoración específica de cuál debería ser el rol urbano de su posible materialización en cada caso.

El paisaje que hemos llamado estado actual da buena cuenta de la fricción diferencial que caracteriza el área metropolitana. Los lugares privilegiados pueden dibujarse, a grandes rasgos, como: (0) un conjunto de lugares centrales en Barcelona - un paquete comprendido por la Av. Diagonal, Av. Meridiana, Rda Litoral, Av. del Paral.lel, Gran Via de Carles III y, más puntalmente, la Torrassa y el entorno de plaza Europa; (1) el eje Besós "C-58 - C-58/C-33";(2) el eje Llobregat "A-2 - B-23 - AP-7"; (3) el eje C-32 y (4) el eje de la C-16. Se trata, respectivamente, de (0) la ciudad compacta, $(1,2)$ las dos brechas de comunicación con el prelitoral catalán, (3) el eje costero hacia el sudoeste, y (4) el eje de penetración que se construyó a golpe de ferrocarril a principios del siglo pasado, con su posterior consolidación viaria mediante los llamados Túneles de Vallvidrera.

El escenario transformado revela una concentración de mejoras de reequilibrio que privilegian a los ejes (1), (2) y (3), en detrimento del eje (4). Este es un escenario deseable, en la medida en que los ejes (1) y (2) articulan una constelación importante de centros y subcentros en el Área Metropolitana de Barcelona (véase el planeamiento territorial de la Región Metropolitana de Barcelona, Generalitat de Catalunya, 2010)

Con todo, se observa un planteamiento que entronca claramente con los resultados de otros estudios similares, que también han centrado su atención en la importancia de la accesibilidad que confieren las redes contemporáneas, como instrumento de análisis y de toma de decisiones en relación a la estructura urbana. La necesidad de trabajar la relación entre la configuración espacial y los flujos de interacción se ha señalado como indispensable (Batty, 2009; Burger y Meijers, 2012; Hillier, 1999). Batty (2013), afirma, en este sentido, que para comprender el espacio debemos comprender los flujos, y para comprender los flujos es necesario entender las redes. En esta misma dirección, toma sentido la formulación del concepto de urbanismo de las redes propuesto por Dupuy (1991).

En este contexto, el trabajo realizado a partir de isolíneas de accesibilidad confirma el potencial de este tipo de análisis, corroborando los hallazgos de trabajos similares y poniendo de manifiesto el alcance de las nuevas aportaciones. Los trabajos de Gómez y de Solà-Morales (1971) y Herce (2005) en el contexto geográfico que nos ocupa, la producción científica más reciente que ya ha combinado el uso de los GTFS con las isócronas de accesibilidad (ver, p. ej., Lee y Miller, 2018), así como la revisión de múltiples estudios de movilidad realizados por consultoras especializadas, ya dan cuenta de la utilidad de este tipo de planteamiento. Sin embargo, el uso específico de la accesibilidad integral a partir de la construcción y simulación de una red multimodal de transporte público basada en GTFS que integra el modo a pie para el ámbito del Área Metropolitana de Barcelona, supone una nueva contribución.

Finalmente, es necesario señalar las limitaciones que impone el propio planteamiento. La formulación de los escenarios que hemos dibujado incluye los conceptos de centralidad y de accesibilidad de una forma imbricada y parcial. La noción de accesibilidad la hemos limitado a la 
Mercadé Aloy, J., Magrinyà Torner, F., Cervera Alonso de Medina, M. (2020): "Revelando las centralidades del transporte público mediante SIG y GTFS: una propuesta de reequilibrio urbano para el Área Metropolitana de Barcelona", GeoFocus, $n^{\circ} 25$, p. 27-46. http://dx.doi.org/10.21138/GF.657

propia configuración espacial de las redes de transporte público, excluyendo en todo momento los denominados factores de utilidad, oportunidad y de comportamiento, tomando el tiempo de viaje encapsulado en los GTFS como única sofisticación. La noción de centralidad, en la misma línea, se ha limitado a la observación del rol de posición de los nodos en el espacio-tiempo de viaje del conjunto metropolitano, descartando, pues, los otros múltiples ingredientes que confieren sentido urbano a dicho concepto.

\section{Conclusiones}

Se ha planteado una estrategia de refuerzo de intercambiadores potenciales de la red ferroviaria a partir del concepto de accesibilidad que, a su vez, se ha identificado como un ingrediente indispensable para el refuerzo de centralidades, dirigido a formar parte de estrategias de reequilibrio urbano.

Las isócronas de accesibilidad permiten comprender el mosaico de lugares del Àrea Metroplitana en función de su posición en el conjunto. De la misma manera, la identificación de nuevas oportunidades de intercambio entre redes de transporte público -Torrassa, Riu Sec, GlòriesClot y bypass Montcada Bifurcació- nos permite alcanzar el objetivo de un nuevo escenario mejorado. Concretamente, se observa una mayor integración de los ejes (1) "C-58 + C-58/C-33", (2) "A-2 + B-23 + AP-7" y (3) "C-32", indispensable para la construcción de una futura estructura urbana más sostenible y socialmente equilibrada.

Las limitaciones de esta aproximación se concentran, en primer lugar, en la elección aislada de la accesibilidad como instrumento de lectura e indicador para evaluar escenarios de propuesta. Ello supone prescindir de una lectura de la configuración espacial y de sus densidades esencialmente, patrones de localización de la actividad, forma y urbanidad-, por bien que la accesibilidad permita aunar aspectos de dimensión morfológica y funcional simultáneamente.

En segundo lugar, el hecho de no considerar el factor oportunidad -todos los orígenes y destinos tienen el mismo peso relativo- reducen el análisis del grafo del transporte público a su geometría e impedancias. Lejos de plantearse únicamente como una limitación, ello permite centrarse en la potencialidad de posición de los lugares metropolitanos con independencia de su naturaleza.

Finalmente, se quiere poner de manifiesto la facilidad de integración de los resultados obtenidos con otras variables descriptivas de la ciudad sostenible -forma urbana, usos del suelo, salud, energía y equidad. En el caso del Área Metropolitana de Barcelona, se encuentra en fase de redacción el Plan Director Urbanístico metropolitano. El conjunto de reflexiones que se realicen en torno a las estrategias de centralidad urbana y de integración de lugares -de los más remotos a los más centrales- deberán considerar la accesibilidad con transporte público inevitablemente.

\section{Referencias bibliográficas}

Allen, J. (2019): "Using Network Segments in the Visualization of Urban Isochrones", Cartographica: The International Journal for Geographic Information and Geovisualization, 53, 4, pp. 262-270. 
Mercadé Aloy, J., Magrinyà Torner, F., Cervera Alonso de Medina, M. (2020): "Revelando las centralidades del transporte público mediante SIG y GTFS: una propuesta de reequilibrio urbano para el Área Metropolitana de Barcelona", GeoFocus, $n^{\circ} 25$, p. 27-46. http://dx.doi.org/10.21138/GF.657

AMB (2017): Transició a la Mobilitat Sostenible de l'AMB. Taula d'Infraestructures per a una Transició a una Mobilitat Sostenible. Ricard Riol. Promoció del Transport Públic. Disponible en http://www3.amb.cat/repositori/ESTUDIS\%20METROPOLITANS/Estrategics/PE_PE_Transicio_ Mobilitat_Sostenible.pdf

AMB (2018): L'accessibilitat al transport públic. Metodologia pel càlcul de l'accessibilitat al transport públic a l'àrea metropolitana de Barcelona. Disponible en https://docs.amb.cat/alfresco/api/-default-/public/alfresco/versions/1/nodes/2b3bfac6-f4a0-40c8b8e2552a50e397af/content/Accessibilitat+al+transport+p\%25C3\%25BAblic_SPDU?attachment=false\& mimeType $=$ application/pdf \&sizeInBytes $=17879434$

Anas, A., Arnott, R., Small, K. A. (1998): "Urban Spatial Structure", Journal of Economic Literature, 36, 3, pp. 1426-1464.

Antrop, M. (2004): "Landscape change and the urbanization process in Europe", Landscape and Urban Planning, 67, 1, pp. 9-26. https://doi.org/10.1016/S0169-2046(03)00026-4

Área Metropolitana de Barcelona (n.d.): L'àrea metropolitana. [consulta 08-03-2018]. Disponible en http://www.amb.cat/s/web/area-metropolitana/area-metropolitana.html

Banister, D. (2008): “The sustainable mobility paradigm”, Transport Policy, 15, 2, pp. 73-80.

Batty, M., Besussi, E., Chin, N. (2003). Traffic, urban growth and suburban sprawl. (CASA Working Papers 70). Centre for Advanced Spatial Analysis (UCL): London, UK.

Batty, M., Besussi, E., Maat, K., \& Harts, J. J. (2004): "Representing multifunctional cities: Density and diversity in space and time", Built Environment, 30, 4, pp. 324-337. https://doi.org/10.2148/benv.30.4.324.57156

Batty, M. (2009): "Accessibility: in search of a unified theory", Environment and Planning B: Planning and Design, 36, 2, pp. 191-194.

Batty, M. (2013): The New Science of Cities. The MIT Press.

Burger, M., Meijers, E. (2012): "Form Follows Function? Linking Morphological and Functional Polycentricity", Urban Studies, 49, 5, pp. 1127-1149.

Busquets, J. (1989): "Arquitectura de la nova centralitat = Architecture of the new centrality", Quaderns d'arquitectura $i$ Urbanisme, 183, pp. 105-111. Disponible en https://www.raco.cat/index.php/QuadernsArquitecturaUrbanisme/article/view/231079/338980

Calvo Palacios, J.L., Alonso Logroño, M.P., Pueyo Campos, A., Jover Yuste, J.M. (1993): "Matización de los valores cartográficos de accesibilidad por carretera de la España Peninsular en función de la variable demográfica (1992)", IV Jornadas de la Población Española, 191-200. Universidad de la Laguna.

Cherkassky, B. V., Goldberg, A. V., \& Radzik, T. (1996): "Shortest paths algorithms: Theory and experimental evaluation", Mathematical Programming, Series B, 73, 2, pp. 129-174.

Christaller, W. (1966): Central places in southern Germany. Prentice Hall. 
Mercadé Aloy, J., Magrinyà Torner, F., Cervera Alonso de Medina, M. (2020): "Revelando las centralidades del transporte público mediante SIG y GTFS: una propuesta de reequilibrio urbano para el Área Metropolitana de Barcelona", GeoFocus, $n^{\circ} 25$, p. 27-46. http://dx.doi.org/10.21138/GF.657

Dalvi, M. Q., (1978): "Behavioural modelling, accessibility, mobility and need: concepts and Measurement", D. A. Hensher and P. R. Stopher (Ed.): Behavioural Travel Modelling. London, Croom Helm, pp. 639-653.

Dupuy, G. (1991): L'urbanisme des réseaux: Théories et méthodes. Paris, Armand Colin.

ESRI. (n.d.): ArcGIS Network Analyst. [Consulta: 8-06-2019]. Disponible en https://desktop.arcgis.com/es/arcmap/latest/extensions/network-analyst/what-is-network-analyst.htm

Fayyaz S., S. K., Liu, X. C., \& Zhang, G. (2017): "An efficient General Transit Feed Specification (GTFS) enabled algorithm for dynamic transit accessibility analysis.", PLoS ONE. https://doi.org/10.1371/journal.pone.0185333

Fleming, D. K., Hayuth, Y. (1994): "Spatial characteristics of transportation hubs: centrality and intermediacy", Journal of Transport Geography, 2, 1, pp. 3-18.

Font Arellano, A. (2012): Patrons urbanistics de les activitats econòmiques : Regió Metropolitana de Barcelona $=$ Urban patterns of economic activities : Barcelona Metropolitan Region. Barcelona, Institut d'Estudis Territorials.

Font Arellano, A., Llop, C., Vilanova i Claret, J. M. (1999): La Construcció del territori metropolità : morfogènesi de la regió urbana de Barcelona. Barcelona, Area Metropolitana de Barcelona.

Freeman, L. C. (1977): “A set of measures of centrality based on betweenness”, Sociometry, 40, pp. $35-41$.

Friedmann, J., Miller, J. (1965): "The urban field", Journal of the American Institute of Planners, 31, 4, pp. 312-320.

Galton, F. (1881): "On the construction of isochronic passage-charts.", Proceedings of the Royal Geographical Society and Monthly Record of Geography, pp. 657-658.

Garrison, W. L. (1960): "Connectivity of the interstate highway system", Papers in Regional Science, 6, 1, pp. 121-137.

Generalitat de Catalunya. (2010). Pla territorial metropolità de Barcelona. Barcelona, Generalitat de Catalunya. [Consulta: 10-07-2019]. Disponible en http://territori.gencat.cat/es/01 departament/05 plans/01 planificacio territorial/plans territorials nou/territorials parcials/ptp metropolita de barcelona/

Geurs, K. T., van Wee, B. (2004): "Accessibility evaluation of land-use and transport strategies: Review and research directions", Journal of Transport Geography, 12, 2, pp. 127-140.

Goliszek, S., \& Połom, M. (2016): “The use of general transit feed specification (GTFS) application to identify deviations in the operation of public transport at morning peak hours on the example of Szczecin", Europa XXI. https://doi.org/10.7163/eu21.2016.31.4

Gómez, J. L., de Solà-Morales, M. (1971): Una medida de accesibilidad: aplicación a la comarca de Barcelona. Laboratorio de Urbanismo de Barcelona.

Hadas, Y. (2013). Assessing public transport systems connectivity based on Google Transit data. Journal of Transport Geography. https://doi.org/10.1016/j.jtrangeo.2013.09.015 
Mercadé Aloy, J., Magrinyà Torner, F., Cervera Alonso de Medina, M. (2020): "Revelando las centralidades del transporte público mediante SIG y GTFS: una propuesta de reequilibrio urbano para el Área Metropolitana de Barcelona", GeoFocus, $n^{\circ} 25$, p. 27-46. http://dx.doi.org/10.21138/GF.657

Hagerstrand, T., (1970): "What about people in regional science?", Regional Science Association, 24, 1, pp. 6-21.

Haggett, P., Chorley, R. J. (1969): Network analysis in geography. London, Edward Arnold.

Hall, P., Pain, K. (2006): The Polycentric Metropolis : Learning form mega-city regions in Europe.

Hall, P. (1997): "Modelling the post-industrial city", Futures, 29, 4, pp. 311-322.

Hansen, W. G. (1959): "How accessibility shapes land use", Journal of the American Institute of Planners, 25, 2, pp. 73-76.

Hanson, J. (1998): Decoding homes and houses. Cambridge, Cambridge University Press.

Hanson, S. (1986): The geography of urban transportation. New York, The Guilford Press.

Hart, T. (2001): "Transport and the City", en Paddison, R. (Ed): Handbook of Urban Studies. University of Glasgow, pp. 102-123.

Heitzman, B. (n.d.): XLS Tools for Google Transit. [Consulta: 8-06-2019]. Disponible en https://sites.google.com/site/rheitzman/

Herce, M. (2005): "Urbanización, precios del suelo y modelo territorial: La evolución reciente del Área metropolitana de Barcelona.”, Eure, 31, 939, pp. 35.51.

Herce, M., Magrinyà, F. (2002): La Ingeniería en la evolución de la urbanística. Barcelona, Edicions UPC.

Hillier, B. (1999): "Centrality as a process: accounting for attraction inequalities in deformed grids", Urban design international, 4, 3-4, pp. 107-127.

Hillier, B. (1996): Space is the Machine: A Configurational Theory of Architecture. Cambridge, Cambridge University Press.

Hillier, B., Hanson, J. (1984): The social logic of space. Cambridge, Cambridge university press.

Indovina, F. (1990): La Città diffusa. Venezia, Istituto universitario di architettura di Venezia. Dipartimento di analisi economica e sociale del territorio.

Ingram, D. R. (1971): “The Concept of Accessibility: A Search for an Operational Form.”, Regional Studies, 5, 2, pp. 101-107.

Kansky, K. J. (1963): Structure of transportation networks: relationships between network geometry and regional characteristics.

Kok, R., (1951): "Isochronenkaarten voor het locale en regionale openbaar personen vervoer van s'Gravenhage", T ijdschrift voor economische en sociale geographie, 17, pp. 261- 278.

Lee, J., Miller, H. J. (2018): "Measuring the impacts of new public transit services on space-time accessibility: An analysis of transit system redesign and new bus rapid transit in Columbus, Ohio, USA", Applied Geography, 93, pp. 47-63.

López-Escolano C., Pueyo Campos Á., Postigo Vidal R., Alonso Logroño M. P. (2016): "Valoración y representación cartográfica de la accesibilidad viaria en la españa peninsular: 19602014. (2017)", GeoFocus (Artículos), 18, pp. 169-189. 
Mercadé Aloy, J., Magrinyà Torner, F., Cervera Alonso de Medina, M. (2020): "Revelando las centralidades del transporte público mediante SIG y GTFS: una propuesta de reequilibrio urbano para el Área Metropolitana de Barcelona", GeoFocus, $n^{\circ} 25$, p. 27-46. http://dx.doi.org/10.21138/GF.657

Lösch, A. (1954): The Economics of Location (translated by William H. Woglom). New Haven, Yale University Press.

Magrinyà, F. (2019): Reflexió estratègica metropolitana per a un territori resilient. Barcelona, Àrea Metropolitana de Barcelona.

Mangin, D. (2004). La Ville franchisée: formes et structures de la ville contemporaine. Paris, Editions de la Villette.

McHugh, B. (2013): "Pioneering Open Data Standards: The GTFS Story", en Goldstein, B. (Ed.): Beyond Transparency - Open Data and Future of Civic Innovation. San Francisco, Code

Mercadé Aloy, J., Magrinyà Torner, F., Cervera Alonso de Medina, M. (2019): "Medidas de centralidad y escala intermedia: el potencial estructurante de la red viaria en el Vallés Oriental.", ACE: Architecture, City and Environment, 13, 39, pp. 11-36. https://doi.org/10.5821/ace.13.39.5302

Monkhouse, F. J., Wilkinson, H. R., (1971) (1st edition 1952): Maps \& diagrams. London, Methuen.

Monzón de Cáceres, A. (1988): "Los indicadores de accesibilidad y la planificación del transporte: Concepto y clasificación", Revistas del Ministerio de Transporte, Turismo y Comunicaciones, 35, pp. 11-18.

O'Sullivan, D., Morrison, A., Shearer, J. (2000): "Using desktop GIS for the investigation of accessibility by public transport: An isochrone approach", International Journal of Geographical Information Science, 40, 1, pp. 85-104.

Porta, S., Crucitti, P., Latora, V. (2006): "The network analysis of urban streets: A primal approach", Environment and Planning B: Planning and Design, 33, 5, pp. 705-725.

Rowe, K., (1953): “The journey to work on Merseyside”, Advancement of Science, 10.

Stewart, J.Q., (1947): "Empirical mathematical rules concerning the distribution and equilibrium of population", Geography Review, 37, pp. 461-485.

Vickerman, R. W. (1974): "Accessibility, Attraction, and Potential: A Review of Some Concepts and Their Use in Determining Mobility", Environment and Planning A: Economy and Space, 6, 6, pp. 675-691.

Volchenkov, D., Blanchard, P. (2008): "Scaling and universality in city space syntax: Between Zipf and Matthew", Physica A: Statistical Mechanics and Its Applications, 387, 10, pp. 2353-2364.

Wilson, A.G., (1970): Entropy in Urban and Regional Modelling. London, PION.

Wilson, A.G., (1971): "A family of spatial interaction models, and associated developments", Environment and Planning, 3, 1, pp. 1-32. 